\title{
Greetings as a Politeness Strategy in EFL Distance Learning Students' Official Emails
}

\author{
Mohammad Almoaily \\ Department of English Language and Literature, College of Arts, King Saud University, Kingdom of Saudi Arabia
}

Copyright $\mathrm{C} 2018$ by authors, all rights reserved. Authors agree that this article remains permanently open access under the terms of the Creative Commons Attribution License 4.0 International License

\begin{abstract}
The current study attempts to discover English as a Foreign Language (EFL) distance learning male students' awareness of email greetings as a politeness strategy in English computer-mediated communication (CMC). To this end, 200 email messages sent from distance learning students at King Faisal University, Saudi Arabia, to their graduation project supervisor were analyzed. The degree of formality of these messages was very high for two main reasons. First, all of the email messages comprised instances of first-time contact with the supervisor. Second, the social distance between the students and their supervisor was high. Hence, the students were expected to use formal email greetings. The emails sent by the analyzed sample were put into three categories: begun with formal greetings, started by informal greetings, and null-greeting emails. Contrary to expectations, only $16.5 \%$ used formal English email greetings. The remaining students chose religious greetings $(20.5 \%)$, less formal greetings $(7 \%)$, or null greetings $(56 \%)$. The large number of null greeting emails suggests that the students' awareness of greetings as a politeness strategy was low. Hence, the study concluded with implications to ensure increasing EFL students' awareness of politeness strategies in $\mathrm{CMC}$.
\end{abstract}

Keywords Politeness, Greeting, Face, Email, Distance Learning

\section{Introduction}

Over the last few years, distance learning programs have enabled many people worldwide to attend online courses in which they can learn from and interact with instructors and other students via interactive distance learning platforms. Unlike the norm in many traditional classrooms, the social distance between the people involved in distance learning (i.e., the students and their instructors) is very high. Indeed, distance learning platforms cater for people from various ethnic, religious, geographical, and linguistic backgrounds who have little, if any, knowledge of each other. This form of interaction, which entails a high social distance, a high level of formality, and different status levels in student-instructor communication, requires knowledge of politeness strategies to ensure that the learning process is not hindered by unintentional face-threatening (i.e., impolite) acts (FTAs). Hence, the purpose of the current study was to assess EFL distance learning students' use of email greetings as a politeness strategy when communicating with their graduation project supervisors. The emails used by the sample were classified into three groups: having formal greetings, having less formal/informal greetings, and null greeting emails. The analysis of 200 email messages sent by male Saudi EFL students in a distance learning program revealed that the majority of the researched students seemed to have little knowledge of what type of greetings to use in formal email messages sent in English. This is despite the fact that all the researched students were at the final stage of obtaining a BA degree in English. Thus, one of the main recommendations of this study is to ensure that EFL distance learning students are oriented with politeness strategies for use in computer-mediated communication (CMC).

\section{Literature Review}

Since Goffman's [1] face theory, which suggests that people try to reinforce/maintain their face (i.e., public self-image) whenever they engage in social interactions, research on politeness has garnered the attention of many researchers in the fields of pragmatics and sociolinguistics. One of the most influential theories on politeness is the work of Brown and Levinson [2]. They proposed a universal model of politeness based on Goffman's face theory. In their politeness model, they suggested that speakers and hearers perform politeness acts to protect their faces as well as their interlocutors' faces from being 
damaged by FTAs. Thus, this model distinguishes between positive and negative face as well as positive and negative politeness. Individuals have the need to be respected and valued by others, an instinctive human need that is referred to as positive face. Negative face, on the other hand, refers to individuals' will to be free from imposition. Based on this distinction, speech acts that protect other people's positive face are classified as positive politeness strategies while negative politeness speech acts seek to protect others' negative face. In turn, lack of adherence to these two kinds of politeness may lead to FTAs, which are also characterized as either negative or positive.

Although no definition of linguistic politeness has been agreed upon, Nwoye [3:309] suggests that there is an overall agreement that it includes "verbal strategies for keeping social interaction friction free". It should be noted, however, that politeness strategies differ from culture to culture. Hence, data produced by EFL learners can be considered a valuable recourse for researchers interested in cross-cultural politeness studies as we will see in the review of the studies below. Another issue that is worth considering here is that linguistic politeness strategies also vary depending on the type of relationship between people. Holmes [4] suggests that people who do not know each other have a high social distance in their relationship and hence are expected to pay more attention to politeness strategies when communicating with each other. Similarly, when communicating with a person of a higher social status (e.g., one's manager or teacher), the speaker is expected to use politer forms than they would use with people of the same social status. Formality can also have a great impact on politeness strategies. Indeed, one is expected to use polite expressions in formal domains such as religion, work, and education. Finally, age can also be a factor that affects politeness levels as younger people are expected to be politer when communicating with older people.

Brown and Levinson's [2] politeness model has, as detailed in the sub-sections below, been widely accepted by many researchers and hence implemented in a large body of empirical cross-cultural research in various fields such as language acquisition, social interaction, and online communication. It should be noted, however, that this model was not free from criticism and alternative ways to understanding the concept of politeness. Once of the strongest criticisms to this model is that it assumes that people prefer to avoid impoliteness at all times. This is indeed not always the case as people sometimes deliberately avoid politeness strategies, especially when challenging someone with an opposing view, see [5-7]. Brown and Levinson's model, however, seems suitable for this study as it studied linguistic politeness in a case where students should, and where expected to, be polite.

The sub-sections below review a number of studies on politeness in the relevant fields to this study (namely, social interaction, online communication, and EFL).

\subsection{Politeness in Real-time Social Interaction}

Brown and Levinson's [2] model for politeness discussed above is proposed to be universal across cultures. Therefore, in their edited volume, Zarobe and Zarobe [8] compiled a number of studies on politeness across different cultures/languages; for example, Polish by Ogiermann [9], Turkish by Zeyrek [10], and Chinese by Jiang [11]. The politeness model has also been implemented in comparative gender studies in non-Western communities. For example, Aliakbari and Moalemi [12] examined the positive and negative politeness strategies used by 30 male and female Iranian students when communicating with university service providers (e.g., librarians, lab technicians, and waiters). Their study revealed that female participants used politer strategies than male participants. Similar findings were also found in another study in the Middle-Eastern context in which Al-harahsheh [13] investigated the employment of silence as a politeness strategy by 12 male and 12 female Jordanian university students in casual conversations. Across different genders, silence was used as a politeness strategy among strangers. Wagner [14] also investigated politeness in apologizing in Cuernavaca (a Spanish variety). Unlike many other studies on politeness in face-to-face communication, Wagner analyzed naturally occurring data. This has the benefit of analyzing politeness strategies accurately. Indeed, an FTA is less likely to occur in a made-up situation, especially in the presence of a researcher and video recording equipment.

Despite the implementation of Brown and Levinson's [2] model in many non-Western communities, there has been some criticism of this theory with some researchers questioning its viability in non-Western cultures, or, at the very least, accusing the model of being Western-biased, see [15]. Hence, Hill et al. [16] hypothesized an alternative model to Brown and Levinson's in which they distinguished between two types of politeness: discernment, which is the tendency for speakers to conform to the socially agreed-upon norms in various situations, and volition, an aspect of politeness that allows the speaker to choose from various politeness acts. They suggested that Western-based research on politeness has not paid much attention to discretion despite its importance in Japanese culture and despite its existence as a politeness strategy in American English and most likely in all other languages/varieties worldwide. Both models suggest that politeness is a universal phenomenon. Different cultures, however, may have their own implications of Brown and Levinson's or Hill et al.'s models of politeness. This is indeed what Hill et al. [16] found when they compared variations in politeness in Japanese and American informants' requests. Both groups were sensitive to distance and status but Japanese informants were more sensitive to discernment than the American sample. 
Moreover, high pitched voice may be interpreted as a polite gesture by hearers in some cultures, while a lowered pitch is used as a politeness strategy in Korean [17]. The next section addresses linguistic politeness in online communication, a rather different form of interaction that mostly involves the use of texts where the phonological aspects of linguistic politeness are often nonexistent.

\subsection{Politeness in Online Communication}

Computer mediated communication (CMC) differs from face-to-face interaction in many ways. For example, the anonymity and physical separation between people communicating online allows people to construct alternative identities [18]. Indeed, people engaged in CMC often do not see one another. This affords them more control over their mental state, especially in asynchronic communication such as email. This is not to assume that politeness is achieved more easily in CMC. In fact, it can be even more challenging than face-to-face interaction in that $\mathrm{CMC}$ has restrictions that are difficult to avoid, such as the absence of prosodic cues that people use to clarify meaning and to demonstrate politeness [19]. Such differences between face-to-face interaction and CMC called for the establishment of politeness norms for online communication, known as netiquette, see [20-22]. These rules for online politeness include, but are not limited to, politeness acts such as respecting other people's time and privacy and not forgetting that one is dealing with another human at the other end. These politeness acts are never different from what people expect in face-to-face interaction. Yet, it is of great importance to keep them in mind when communicating online as they are easily overlooked. For example, a student is not expected to enter their instructor's office and submit their term project without greeting the instructor beforehand. Yet, the same student might submit their paper via email without using any form of greeting.

The increasing need for online communication as well as the great deal of multi-functionality for CMC calls for research in the various ways in which politeness is achieved. Email, for example, has evolved from a medium of communication that is primarily used for business interaction to a tool that is also used for personal communication. Therefore, (im) politeness in communication via email has been evolving over the past two decades [19].

Hence, a large number of researchers have endeavored to investigate politeness in CMC. Our focus here will be on studies that have addressed politeness in email communication. In an attempt to compare politeness between requests made via email and voicemail, Duthler [23] analyzed requests made by 151 participants and found that requests made via email were politer than those via voicemail. They explained this difference by stating that voicemail requires immediate action and thus does not allow people to construct appropriate politeness acts. Email users, on the other hand, have more time to ensure that they adhere to the expected politeness levels by the email recipients. Duthler's findings were consistent with Walther's [24] model, which suggests that CMC facilitates social tasks. In an interesting comparative study, Waldvogel [25] compared two workplace environments, an educational institution and a factory, to see whether the different conditions in these two workplace environments would lead to variation in the use/omission of greetings. The findings suggest that the workplace is a more determining factor of the use of greetings and closings as polite acts than status, gender, or even social distance. These findings are contrary to the established view that distance and social status are more determining factors of politeness (see Holmes [4]). The following section focuses on $\mathrm{CMC}$ in educational settings.

\subsection{Politeness and EFL}

The growing number of online EFL courses and the continuous need for online communication between distance learning students and their instructors (both synchronic and diachronic) call for the importance of offering netiquette tuition to such students. A number of studies on politeness in CMC have raised the importance of such a move. For example, in a recent study, Alsharif and Alyousef [26] investigated the differences in negotiation and (im) politeness strategies in emails sent to university professors by two groups: Australian and Saudi postgraduates. Both groups performed relatively similarly in extended negotiations and hence the authors concluded their research by recommending that international students improve their negotiation techniques by providing more detailed explanations. In a more relevant study to the current research, Vinagre [27] examined politeness in e-mail exchanges in computer-supported collaborative learning. She began her investigation by stressing the importance of developing means for online collaborative learning and how advantageous this can be for students in geographically remote areas. Since participating in collaborative distance learning programs requires constant exchanges with people of high social distance, misinterpretations of linguistic behavior might occur, and hence negative face is always at stake. As a result, Vinagre examined politeness strategies in 11 email exchanges between students, who were learners of English and Spanish as foreign languages, in collaborative learning and found that the participants did not use negative face strategies as often as positive face strategies. Although this can be interpreted as an attempt by students to build solidarity with each other, students' negative face should also be considered. The next section discusses the data and methodology implemented in the current investigation. 


\section{Materials and Methods}

The purpose of the current study was to assess the awareness of EFL distance learning students of email greetings as a politeness strategy. In line with Brown and Levinson's[2] aforementioned theory of face, sending an email to one's instructor with a less formal greeting or with no greeting at all can be interpreted as an FTA. Starting the email with a formal greeting, on the other hand, is a sign of the student's awareness of strategies for protecting the email recipient's positive face, see Waldvogel [25]. Hence, I analyzed the greetings used in 200 email messages sent to me, as a graduation project supervisor, by the 200 participating students in the academic years 2014-2015 and 2015-2016. The aim of this analysis was to determine what type of greetings these distance learning students used when communicating with their instructor for the first time. There were three possible conditions for the greetings: formal, less formal/informal, and null. All the students investigated in the current study were male, non-native speakers of English ${ }^{1}$, and were in their final year of the BA Program in English (distance learning) offered by King Faisal University (KFU). Hence, the effects of gender difference and variations in English competence are minimized.

Once students enrolled in the program have completed the list of program courses over seven semesters (three and a half academic years), they are required to write a graduation project in the last semester. In this graduation project, they write a research proposal over the course of 14 weeks. The research proposal is limited to research in the areas of linguistics, literature, and translation. Since writing the research proposal requires assistance in choosing the topic, narrowing it down, writing the research questions, choosing the appropriate methodology for data collection and analysis, etc., a supervisor is assigned to every 50 students to guide them through the process of writing their research project. Most students are located in geographically distant areas from the university main campus. Therefore, face-to-face interaction between the students and their supervisor is difficult to achieve. Hence, students were given deadlines for important phases in writing the research proposal (such as deciding on the topic, sending the research questions, sending the first draft of the proposal, etc.) and they were asked by the supervisor to send these requirements via email in accordance with the set deadlines. Despite the fact that both the instructor and students were native speakers of Arabic, the language of communication was English.
To minimize the impact on politeness of constant communication, whereby people become more relaxed as they continue their linguistic exchange and thus are not expected to continue using politeness strategies (see Holmes [4]), all the email messages analyzed in the current study comprise instances of first time communication with the supervisor. Another factor that led us to expect the use of formal greetings was the high social distance between the students and their supervisor. The students were enrolled in a distance learning program and none of them had had previous contact with their supervisor. Even if the supervisor had taught some of the students' previous courses, there had been no direct communication as students were only required to watch video-recorded lectures in the program courses and to complete assignments via Blackboard. In addition to social distance, power is another factor that is expected to result in politer greetings. Indubitably, teachers have more social power than students which, in turn, leads to expecting students to use polite expressions when communicating with their teachers.

Unlike many other research projects on politeness (see the review above), the data used in the current paper are naturally occurring and thus are more precise determiners of politeness strategies than experimental stimuli-reaction studies. Indeed, participants in such studies are expected to attempt to avoid FTAs and use more politeness strategies as they are likely to behave more politely. In other words, they provide data on what should be done rather than what is actually done in real-life communications. In naturally occurring data, however, people behave spontaneously and are not behaving more politely than usual due to their participation in a politeness experiment.

The greetings used in the email messages under investigation were categorized into three types. The first type comprised formal greetings, which could be: Religious Greetings (RG), Time Related (TR), or the common form Dear X (DX). The second type comprised less formal email greetings. Examples of this type are: Greetings (GR), Hello (H1), and Hi (H2). The third type comprised null greetings (NG), in which the student sent their research topic, inquiry, etc., in an attached file or in the body of the email, but without any greetings. Table 1 below summarizes these three categories and provides examples of them: 
Table 1. Types of greeting

\begin{tabular}{|c|c|c|c|c|c|c|c|}
\hline \multicolumn{4}{|c|}{ Formal } & \multicolumn{3}{c|}{ Less formal/Informal } & NG \\
\hline Type & RG & DX & TR & GR & H1 & H2 (X) & $\emptyset$ \\
\hline Examples & $\begin{array}{c}\text { Assalamu } \\
\text { Alaykom (peace be } \\
\text { upon you) }\end{array}$ & $\begin{array}{c}\text { Dear, } \\
\text { Dear Dr. }\end{array}$ & $\begin{array}{c}\text { Good Morning/ } \\
\text { afternoon/ } \\
\text { evening }\end{array}$ & Greetings & $\begin{array}{c}\text { Hello, } \\
\text { Hello Dr. }\end{array}$ & $\begin{array}{c}\text { Hi, } \\
\text { Hi X, X }\end{array}$ & $\emptyset$ \\
\hline
\end{tabular}

In Table 1 above, the instances of $\mathrm{NG}$ or $\mathrm{H} 1$ and $\mathrm{H} 2$ were not classified as impolite acts although they may pose a threat to the positive face of the email recipient and are indeed FTAs. This is due to the fact that not using formal greetings is most likely to result from lack of awareness of formal email greetings as politeness strategies. It is unexpected for students to purposefully commit an FTA. Indeed, this is highly unlikely as students are expected to build a positive relationship with their supervisor in their first contact with them. Other factors that may lead to impoliteness, such as poor working conditions (as reported by Waldvogel [25]) are also unlikely because the students and the professor have no prior contact. Hence, the various types of greeting were interpreted as a continuum of awareness of greetings as a positive face strategy in $\mathrm{CMC}$, from the strongest indicator on the left side of the table to the weakest indicator on the right. The next section presents the study findings and discusses the potential interpretation of the data.

\section{Results and Discussion}

As detailed in the previous section, the greetings in the 200 email messages sent by the students to their graduation project supervisor were classified into three categories according to the degree of formality (formal, informal, and null). The use of informal greetings or no greetings could be interpreted as signifying a lack of awareness of positive face strategies used in CMC to show solidarity with the email recipient. Table 2 below lists the types of greetings used by the students as well as the number of tokens for each classification:

Table 2. Instances of greetings in each classification

\begin{tabular}{|c|c|c|c|c|c|c|c|c|}
\hline \multicolumn{4}{|c|}{ Formal Greetings } & \multicolumn{3}{c|}{ Less formal/Informal greetings } & NG \\
\hline Type & RG & DX & TR & GR & H1 & H2 (X) & $\emptyset$ \\
\hline $\begin{array}{c}\text { No. of tokens } \\
\text { (percentage) }\end{array}$ & 41 & 28 & 5 & 3 & 6 & 5 & 112 \\
$(20.5 \%)$ & $(14 \%)$ & $(2.5 \%)$ & $(1.5 \%)$ & $(3 \%)$ & $2.5 \%)$ & $(56 \%)$ \\
\hline
\end{tabular}

Contrary to expectations, the least polite classification (NG) had the highest proportion of tokens. One hundred and twelve students (56\% of the sample) contacted their graduation project supervisor for the first time without including any form of greeting in their emails. It seems that the only possible explanation for this large proportion of $\mathrm{NG}$ emails in the data is that the researched students were unaware of the importance of greetings as a politeness strategy in formal CMC. This claim can also be supported by the fact that the conventional greetings in formal emails (i.e., DX variants) were only used by $14 \%$ of the students, as illustrated in Table 3 below.

Seventy-four $(37 \%)$ of the sampled students used formal greetings in their emails. These formal greetings can be further classified into three types: RG, DX, and TR greetings. In the first type, 41 students chose to write the religious greeting ${ }^{2}$ in Arabic (السالم عليكم) 'peace be upon you,' despite having been instructed to use English in all forms of communication. Three of those students chose to

2 The full form of this greeting is (السلام عليكم ورحمة الله وبركاته) 'Gods peace and blessings be upon you'. It can take shorter forms such as 'piece be upon you' or even shortened to (سلام) 'peace'. transliterate this Islamic-Arabic greeting and write it in English letters. This can possibly be explained by the students' attempt to build social relations by signaling shared ethnicity with the supervisor. This solidarity-based act is reported by Holmes [4] as one of the common reasons for code-switching, also see Sert [28] and Walker [29]. Another possible explanation for this use of religious greeting is that students viewed the greeting and body of the email (be it an enquiry or an initial topic for their research) as two separate elements. In other words, they might have considered the greeting to be an irrelevant part of the email, and therefore used a greeting that they would normally use in daily interactions. If this explanation is correct, then it would also explain why the majority of the sampled students did not use any form of greeting in their emails. It is therefore possible that the students considered the greeting to be an irrelevant part of the email they had to send to their supervisor. The other two types of formal greeting are the ones that we expect to find in formal CMC in English, namely DX (14\%) and TR (2.5\%). The second category (DX) took many forms in the data. These variants 
are shown in Table 3 below:

Table 3. Various forms of (Dear) greeting in the data ${ }^{3}$

\begin{tabular}{|l|l|l|l|l|l|l|}
\hline Type & $\begin{array}{l}\text { Dear } \\
+\mathrm{T}+\mathrm{I}+\mathrm{S}\end{array}$ & $\begin{array}{l}\text { Dear } \\
+\mathrm{T}+\mathrm{S}\end{array}$ & $\begin{array}{l}\text { Dear } \\
+\mathrm{T}+\mathrm{I}\end{array}$ & $\begin{array}{l}\text { Dear } \\
+\mathrm{T}\end{array}$ & $\begin{array}{l}\text { Dear } \\
+\varnothing\end{array}$ & Total \\
\hline No. & 4 & 10 & 5 & 5 & 4 & 28 \\
\hline
\end{tabular}

None of the tokens of DX above were written in Arabic. This could be explained by the fact that the word 'dear' in Arabic (i.e., عزيزي) could have been viewed as too intimate by the recipient. The different connotation of the word in Arabic, in addition to the instructions to students to communicate with their instructors in English only, could both have contributed to the absence of the Arabic word for 'dear' in the data. The last type of formal greeting comprises time-related greetings such as "Good morning" and "Good afternoon." These occurred only five times in the data. The number of formal greetings was lower than expected in the corpus (at 37\%). The proportion of greetings typically used in English formal greetings in CMC is even lower (only used in $28 \%$ of the sampled messages).

Less formal greetings were rarely used by the students. The word "greetings" was used by one student only. The Arabic equivalent of this greeting (التحية) was used by two other students. The informal greeting "hello" was used by six students while "hi" was used by five students. This low number of informal $\mathrm{CMC}$ greetings could be explained by students' awareness that these greetings are informal and thus should not be used in formal communication.

The low number of formal greetings, in addition to the large number of NG emails, has a number of implications. The following section lists a number of suggested implications for distance learning programs that use English as the medium of communication and are attended by non-native speakers of English.

\section{Implications}

The data of this study suggest that the majority of the researched students possibly lacked the essential knowledge of positive face politeness strategies typically used in English email messages. Other explanations, such as deliberate avoidance of linguistic politeness seem to be unlikely, as argued in section 4 above. This potential lack of awareness of formal email greetings in English CMC is despite the fact that all the sampled students were in the final stage of a distance learning BA in English program. The lack of knowledge is reflected in the sending of official emails without any form of greeting by $56 \%$ of the sampled students, the use of an Islamic-Arabic religious greeting by $20.5 \%$ of the sample, and the use of informal greetings by

3 Note that $\mathrm{T}$ stands for title, I for initial name, $\mathrm{S}$ for surname.
$7 \%$. This means that in total, $83 \%$ did not use the greetings typically used in official communication. Awareness of politeness strategies in CMC is indeed essential for all EFL students. This need is even greater for distance learning students as $\mathrm{CMC}$ is their learning tool. In addition to using $\mathrm{CMC}$ in their official and unofficial online communication, distance learning students also use CMC to communicate with their peers, course instructors, as well as other faculty in the program. This lack of awareness could lead to unintentional positive and negative FTAs by the students. Hence, the most essential recommendation of this study is to raise the awareness of EFLs in distance learning programs of politeness strategies in CMC. This can be achieved by providing netiquette training once students join these programs. This training should provide students with essential politeness strategies to which they should adhere in CMC. The program which the sampled students are enrolled in has a core course entitled Language and IT in which they are introduced to some topics at the intersection between language and technology, such as CALL and Corpus Linguistics. This course, however, does not take CMC politeness into consideration despite its importance for the students enrolled in the program.

Another suggestion is to encourage the organizers of EFL distance learning programs to design interactive programs, in which students communicate with their instructors and peers throughout the program courses. Such interactive learning environments are expected to allow course instructors to identify areas of incompetency and weakness and to remedy them at earlier stages. The program under investigation offers a one-way communication whereby students attend recorded lectures. The students can still communicate with their instructors via email or phone in all of the courses they attend, but the vast majority of students do not make use of these facilities because they have most of the information they need in the recorded lectures and the content uploaded to Blackboard.

EFL students attending distance learning programs should also be encouraged by their instructors to practice English skills in their free time. Indeed, most of what we learn about language use can be achieved outside the domain of the classroom. For instance, if the sampled students who sent NG emails had read about the greetings used in official emails, which are available on many websites, they would have chosen more formal greetings.

It should also be noted that the above-mentioned recommendations also apply to all students of various majors, as CMC is an inevitable part of every educational setting. Proper use of email greetings is also an essential life skill for all students.

\section{Conclusions}

The current study attempted to measure EFL distance learning students' awareness of the use of formal greetings 
in CMC as a politeness strategy. The greetings used in 200 emails sent by 200 EFL distance learning students were analyzed. Despite the high level of formality of these emails, the high social distance between the senders and recipient, and the higher status of the recipient, the majority of students did not use any form of greeting in their emails. This lack of adherence to greeting norms in English official emails calls for serious steps to raise EFL distance learning students' awareness of politeness strategies in CMC.

The anticipated increase of EFL distance learning programs in the future, as more EFL learners worldwide have access to the internet, increases the need for research that aims at tackling the challenges faced by distance learning programs and how these predicaments can be minimized if not completely solved. Since CMC is the main tool for communication between students and instructors, research on other (im) politeness strategies used by EFL distance learning students is encouraged. Indeed, distance learning programs can be perceived of as international schools with students from different ethnic and cultural backgrounds. Lack of adequate instruction on politeness measures in CMC can lead to communication breakdowns and misconceptions. Thus, research on (im) politeness in these programs could be of great help to both the organizers and students.

The data in the current study can also be compared with similar data from female students. Indeed, approaching this line of research from a sociolinguistic perspective can help us to determine the sociolinguistic groups that are in most need of instruction in politeness strategies in CMC.

\section{Acknowledgements}

The author would like to thank the Deanship of Scientific Research and RSSU at King Saud University for their technical support.

\section{REFERENCES}

[1] E. Goffman. Interaction ritual: Essays on face-to-face behaviour, Penguin, Harmondsworth: Middlesex, 1967.

[2] P. Brown, S. Levinson. Politeness: Some universals in language usage, Cambridge University Press, Cambridge, 1987

[3] O. G. Nwoye. Linguistic politeness and socio-cultural variations of the notion of face, Journal of Pragmatics, 18(4), 309-328, 1992.

[4] J. Holmes. An introduction to sociolinguistics ( $4^{\text {th }}$ ed.), Pearson/Longman, Harlow, 2013.

[5] B. Fraser. Perspectives on Politeness, Journal of Pragmatics, 14, 219-236, 1990.

[6] R. Watts. Politeness, Cambridge University Press,
Cambridge, 2003.

[7] H. Spencer-Oatey. Managing rapport in talk: Using rapport sensitive incidents to explore the motivational concerns underlying the management of relations, Journal of Pragmatics, 34, 529-545, 2002.

[8] L. R. Zarobe, Y. R. Zarobe. Speech acts and politeness across languages and cultures, Peter Lang, New York, 2012.

[9] E. Ogiermann, About Polish politeness. In L. R. Zarobe, Y. R. Zarobe (Eds.). Speech acts and politeness across languages and cultures, 27-52, Peter Lang, New York, 2012.

[10] D. Zeyrek. Thanking in Turkish: A corpus-based study, In L. R. Zarobe, Y. R. Zarobe (Eds.). Speech acts and politeness across languages and cultures, 27-52, Peter Lang, New York, 2012.

[11] X. Jiang. Politeness and facework in Chinese language, In L. R. Zarobe, Y. R. Zarobe (Eds.). Speech acts and politeness across languages and cultures, 27-52, Peter Lang, New York, 2012.

[12] M. Aliakbari, R. Moalemi. Variation of politeness strategies among the Iranian students, Theory and Practice in Language Studies, 5(5), 8, 2015

[13] A. Al-harahsheh. Silence and politeness in Jordanian society, Arab World English Journal, 3(3), 24, 2012

[14] L. C. Wagner. Positive- and negative-politeness strategies: Apologizing in the speech community of Cuernavaca, Mexico, International Communication Studies, 13(1), 9, 2004

[15] S. Kiyama, K. Tamaoka, M. Takiura. Applicability of Brown and Levinson's politeness theory to a non-Western culture: Evidence from Japanese facework behaviors, SAGE Open, 2(4), 2012.

[16] B. Hill, S. Ide, S. Ikuta, A. Kawasaki, T. Ogino. Universals of linguistic politeness: Quantitative evidence from Japanese and American English, Journal of Pragmatics, 10(3), 25, 1986.

[17] L. Brown, P. Prieto. (Im) politeness: Prosody and gesture, In J. Culpeper, M. Haugh, D. Z. Kádár (Eds.). The Palgrave handbook of linguistic (im)politeness, 357-379, Palgrave Macmillan UK, London, 2017

[18] P. Baker. Moral panic and alternative identity construction in Usenet, Journal of Computer-Mediated Communication, $7(1), 2001$

[19] S. L. Graham, C. Hardaker. (Im) politeness in digital communication. In J. Culpeper, M. Haugh, D. Z. Kádár (Eds.). The Palgrave handbook of the psychology of linguistic (im) politeness, 785-814, Palgrave Macmillan, Basingstoke, 2017.

[20] D. Ballam, C. Fullwood. Fluidity of personal boundaries in online social media: Implications for netiquette, Contemporary Ergonomics and Human Factors, 391-399, 2010.

[21] J. Cardenas, M. F. Figueroa, A. Y. Jose, E. K. M Villarreal. Netiquette moral practices and norms in virtual interactions in secondary school students, Innovacion Educativa-Mexico, 15(69), 57-71, 2015. 
[22] L. Scheuermann, G. Taylor. Netiquette: Internet Research-Electronic Networking Applications and Policy, 7(4), 269-273, 1997.

[23] K. W. Duthler. The politeness of requests made via email and voicemail: Support for the hyperpersonal model, Journal of Computer-Mediated Communication, 11(2), $500-521,2006$

[24] J. B. Walther. Computer-mediated communication: Impersonal, interpersonal, and hyperpersonal interaction, Communication Research, 23(1), 3-43, 1996.

[25] J. Waldvogel. Greetings and closings in workplace email, Journal of Computer-Mediated Communication, 12(2), 456-477, 2007.

[26] A. Alsharif, H. Alyousef. Negotiation and impoliteness strategies in Saudi and Australian postgraduate students' emails, Arab World English Journal, 8(4), 19, 2017.

[27] M. Vinagre. Politeness strategies in collaborative e-mail exchanges, Computers \& Education, 50(3), 1022-1036, 2008.

[28] O. Sert. The functions of code-switching in ELT classrooms, The Internet TESL Journal, XI (8), 2005, Retrieved from http://iteslj.org/Articles/Sert-CodeSwitching.html

[29] V. Walker. Codeswitching as a power and solidarity strategy in the foreign language classroom an analysis of language alternation strategies utilised in a Portuguese-English higher education class, Innervate Leading Undergraduate Work in English Studies, 3, 358, 2011, Retrieved from https://www.nottingham.ac.uk/englis h/documents/innervate/1011/1011walkersociolinguistics.p df. 